\title{
Constitutional activation of IL-6-mediated JAK/STAT pathway through hypermethylation of SOCS-I in human gastric cancer
} cell line

\section{KF To*,', MWY Chan', WK Leung', EKW Ng${ }^{3}, \mathrm{~J} \mathrm{Yu}^{2}, \mathrm{AHC} \mathrm{Bai}^{2}, \mathrm{AWI} \mathrm{Lo}^{\prime}, \mathrm{SH} \mathrm{Chu}^{2}, \mathrm{JHM}$ Tong', KW Lo', JJY Sung ${ }^{2}$ and FKL Chan ${ }^{2}$}

'Department of Anatomical and Cellular Pathology, The Chinese University of Hong Kong, Prince of Wales Hospital, Shatin, NT, Hong Kong: ${ }^{2}$ Department of Medicine and Therapeutics, The Chinese University of Hong Kong, Prince of Wales Hospital, Shatin, NT, Hong Kong; ${ }^{3}$ Department of Surgery, The Chinese University of Hong Kong, Prince of Wales Hospital, Shatin, NT, Hong Kong

The interleukin-mediated Janus kinase (JAK)/STAT pathway plays a crucial role in carcinogenesis. Recently, increased STAT3 activity was found in hepatocellular carcinoma and multiple myeloma in which there was silencing of SOCS-I (suppressor of cytokine signalling-I) by gene promoter hypermethylation. We investigated the expression level of interleukin-6 (IL-6) and SOCS-I in gastric cancer cell lines. Expression of SOCS-I correlated with IL-6 level in most of the cell lines, except for AGS cells in which SOCS-I was absent despite a high level of IL-6 production. Methylation analysis by methylation-specific polymerase chain reaction and bisulphite sequencing revealed that CPG island of SOCS-I was densely methylated in AGS cells. Demethylation treatment by 5'azadeoxycytidine restored SOCS-I expression and also suppressed constitutive STAT3 phosphorylation in AGS cells. Moreover, methylation of SOCS-I was detected in 27.5\% (I I of 40) of primary gastric tumours samples, $10 \%$ (one of I0) of adjacent noncancer tissues but not in any (zero of nine) normal gastric mucosa. Methylation of SOCS-I also correlated with the loss of mRNA expression in some primary gastric cancers. In conclusion, this is the first report to demonstrate that hypermethylation of SOCS-I led to gene silencing in gastric cancer cell line and primary tumour samples. Downregulation of SOCS-I cooperates with IL-6 in the activation of JAK/STAT pathway in gastric cancer.

British Journal of Cancer (2004) 9 I, I335-1341. doi:I0.1038/sj.bjc.6602 I33 www.bjcancer.com

Published online 31 August 2004

(c) 2004 Cancer Research UK

Keywords: IL-6; SOCS-I; methylation; STAT3; gastric caner

Gastric cancer is the second most common cause of cancer death worldwide (Pisani et al, 1993). One of the well recognised environmental risk factors for gastric cancer is Helicobacter pylori infection (Graham, 1997). Although this bacterium has been classified as a type I carcinogen by the World Health Organisation (Kuipers and Meuwissen, 1996), the mechanisms by which $H$. pylori causes gastric cancer is not fully understood. It is recognised that there is a strong inflammatory response in $H$. pylori-infected gastric cancer tissues. In particular, upregulation of interleukin- 6 (IL-6) levels is observed in gastric cancer tissue (Yamaoka et al, 1996, 2001). Furthermore, serum IL-6 levels is shown to correlate with prognosis of gastric cancer patients (Wu et al, 1996). These data suggest that the activation of IL- 6 signalling pathway may be important in the development of gastric cancer.

Interleukin- 6 and other interleukin family proteins are thought to be involved in host defense mechanism as well as cancer development (Kabir and Daar, 1995; Wu et al, 1996; Schneider et al, 2000; Giri et al, 2001). The activation of IL-6 signal transduction involves binding to its transmembrane receptor and subsequent activation of the Janus kinase (JAK), which is followed by

*Correspondence: Dr KF To; E-mail: kfto@cuhk.edu.hk

Received 25 February 2004; revised I 5 July 2004; accepted 16 July 2004; published online 31 August 2004 phosphorylation of STAT (STAT1/3) (O'Shea et al, 2002). Phosphorylated STAT protein then translocates into the nucleus with subsequent activation of target genes. One of the STATactivated genes is SOCS-1 (suppressor of cytokine signalling-1). Suppressor of cytokine signalling-1 and its family are proteins containing the $\mathrm{SH} 2$ domains that interact with JAK and prevent activation of STAT, as well as downregulate the JAK/STAT signalling pathways (Endo et al, 1997; Starr et al, 1997). Specifically, SOCS-1 can be rapidly upregulated by IL- 6 and is involved in the downregulation of the IL-6-induced activation of STAT3 (Starr et al, 1997; Nicholson et al, 1999).

Recent findings suggest that the inactivation of SOCS-1 was one of the targets in cancer development. Suppressor of cytokine signalling-1 is downregulated by methylation of the $\mathrm{CpG}$ island in human hepatocellular carcinoma (HCC), multiple myeloma and pancreatic ductal neoplasm (Yoshikawa et al, 2001; Nagai et al, 2002; Fukushima et al, 2003; Galm et al, 2003; Okochi et al, 2003). On the other hand, restoration of SOCS-1 suppressed growth in HCC cell lines and oncogene-activated haematopoietic cells (Yoshikawa et al, 2001; Rottapel et al, 2002). Taken together, these data suggest that SOCS-1 functions as a tumour suppressor in the JAK/STAT pathway.

In the present study, we found that there was downregulation of SOCS-1 gene in gastric cancer cell line AGS due to gene promoter 
hypermethylation. Furthermore, demethylation treatment by $5^{\prime}$ aza-deoxycytidine ( $5^{\prime}$ azaDC) not only restored SOCS- 1 expression in AGS cell but also suppressed constitutive STAT3 phosphorylation. Methylation of SOCS-1 was detected in $27.5 \%$ (11 of 40) of primary gastric tumours samples. We further showed that downregulation of SOCS-1 correlated with the methylation status in primary gastric cancer. This study provides evidence that the activation of JAK/STAT pathway by aberrant SOCS-1 methylation in gastric cancer.

\section{MATERIALS AND METHODS}

\section{Gastric cancer cell lines and tissues}

Gastric cancer cell lines AGS (CRL-1739), SNU-16 (CRL-5974), KATO III (HTB-103), and NCI-N87 (CRL-5822) were obtained from the American Type Culture Collection (ATCC, Rockville, MD, USA), while MKN28 (RCB1000) and MKN45 (RCB1001) were obtained from Riken Cell Bank (Tsukuba, Japan). All cell lines except Kato III were grown in RPMI 1640 medium (Gibco BRL, Gaithersburg, MD, USA) supplemented with $10 \%$ fetal bovine serum (FBS) (Gibco BRL). Kato III was grown in RPMI 1640 medium supplemented with $20 \%$ FBS. All cell lines were kept at $37^{\circ} \mathrm{C}$ in a humidified incubator with $5 \% \mathrm{CO}_{2}$ in air.

In all, 40 primary gastric tumour samples and 10 adjacent noncancer tissues were obtained in Prince of Wales Hospital, Shatin, Hong Kong. Nine normal gastric mucosa from individuals without gastric cancer were also obtained as control. All patients gave informed consent for obtaining the specimens. The median age of gastric cancer patients at the time of diagnosis was 70 years old (range from 34 to 83 ). The male to female ratio was $1.5: 1$. The H\&E-stained sections were reviewed by a pathologist to confirm the diagnosis. In all, 19 cases were intestinal type, 17 cases were diffuse type, and four cases were mixed-type gastric adenocarcinoma.

\section{DNA extraction}

DNA from formalin-fixed paraffin-embedded sections were extracted using High Pure PCR Template Preparation Kit (Boehringer Mannheim, Indianapolis, IN, USA). For extraction of cell lines DNA, phenol/chloroform method was used. H\&E-stained sections from each tumour sample were examined by an experienced pathologist to confirm their histological diagnosis and assess the tumour content. If tumour content was less than $80 \%$, tumour content was enriched by microdissection using a fine needle under a dissection microscope as described previously (Chan et al, 2000).

\section{Methylation-specific polymerase chain reaction (PCR) (MSP) for SOCS-1}

Extracted DNA was bisulphite modified by CpGenome DNA Modification kit (Intergen, Purchase, NY, USA). The modified DNA was subjected to MSP using specific primers for SOCS-1 as described previously (Yoshikawa et al, 2001). Primer sequences, annealing temperatures and the expected product size were listed in Table 1. A measure of $2 \mu \mathrm{l}$ of bisulphite-modified DNA were amplified in a total volume of $25 \mu \mathrm{l}$ containing $1 \times$ PCR buffer II (Applied Biosystems, Foster City, CA, USA), $2 \mathrm{~mm} \mathrm{MgCl}_{2}, 0.25 \mathrm{~mm}$ dNTP, $1 \mu \mathrm{M}$ of each primer and $1 \mathrm{U}$ of AmpliTaq Gold DNA polymerase (Applied Biosystems, Foster City, CA, USA) at $95^{\circ} \mathrm{C}$ for $10 \mathrm{~min}, 38$ cycles of $95^{\circ} \mathrm{C}$ for $30 \mathrm{~s}, 60^{\circ} \mathrm{C}$ for $30 \mathrm{~s}$, and $72^{\circ} \mathrm{C}$ for $30 \mathrm{~s}$, followed by a final extension of $72^{\circ} \mathrm{C}$ for $10 \mathrm{~min}$. In vitro methylated DNA (IVD) (Intergen, Purchase, NY, USA) was used as a positive control for methylation and water was used as a negative control. A measure of $10 \mu \mathrm{l}$ of PCR products were loaded onto nondenaturing $10 \%$ polyacrylamide gels. The gels were then stained with ethidium bromide and visualised under UV illumination.

\section{Bisulphite sequencing for SOCS-1}

Bisulphite-treated DNA was amplified using specific primers for exon 1 region of SOCS-1 gene as reported by Yoshikawa et al (Table 1). The PCR products were cloned into Topo TA cloning kit (Invitrogen, Carlsbad, CA, USA). Five randomly picked clones were sequenced using the dRhodamine Terminator Cycle Sequencing Ready Reaction Kit (Applied Biosystems, Foster City, CA, USA). The sequencing products were separated on an Applied Biosystems 377 automated sequencer (Applied Biosystems, Foster City, CA, USA) and analysed using Applied Biosystems sequencing analysis software.

\section{RNA isolation and reverse transcription-PCR (RT - PCR) for SOCS-1 and $I L-6$}

Total RNA was extracted from frozen human gastric tissues and cell lines by TRIzol reagent (Invitrogen, Carlsbad, CA, USA). Total RNA $(2 \mu \mathrm{g})$ was reverse transcribed into cDNA by MMLV reverse transcriptase (Invitrogen, Carlsbad, CA, USA). The expression of SOCS 1 and IL-6 was examined by PCR using specific primer as listed in Table 1. For amplification of $I L-6$, a touch-down PCR cycle as described by Lin et al (2000a) was used. As an internal control, amplification of $\beta$-actin was performed. The PCR products were electrophoresed on a $1.5 \%$ agarose gel stained with ethidium bromide and visualised under ultraviolet illumination.

Table I PCR primer sequences used

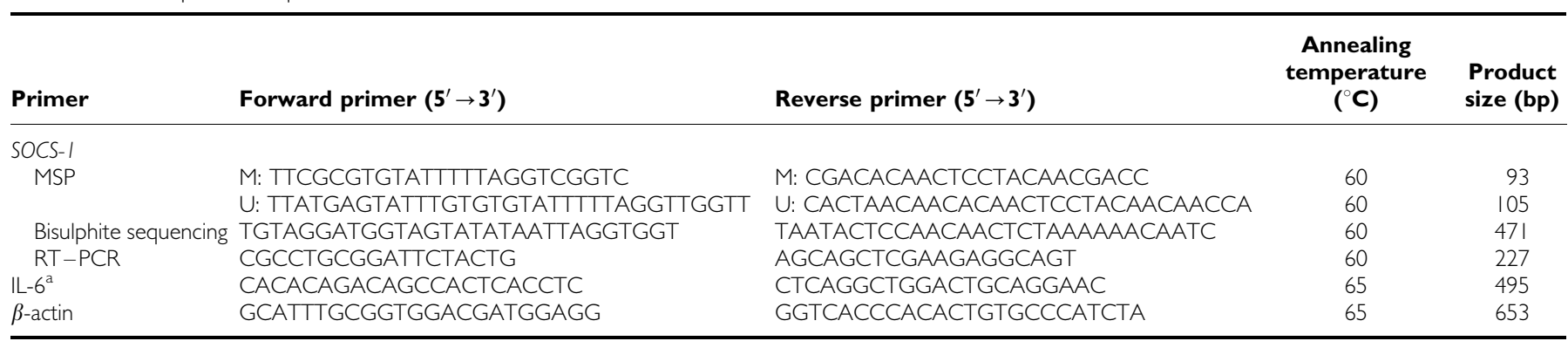

$M=$ methylated primer; $U=$ unmethylated primer; SOCS-I = suppressor of cytokine signalling-I; MSP = methylation-specific PCR; $R T-P C R=$ reverse transcriptionpolymerase chain reaction; IL-6 = interleukin-6. ${ }^{a}$ Touch-down programme starting from $65^{\circ} \mathrm{C}$. 


\section{IL-6 protein measurement}

In vitro IL-6 production from AGS gastric cancer cell line was performed as described previously (Hwang et al, 2003). AGS $\left(5 \times 10^{5}\right.$ cells ml $\left.^{-1}\right)$ were plated into 24 -well plate and cultured for 2 days in triplicate. Interleukin-6 in the supernatant was measured by Quantikine HS human IL-6 immunoassay (R\&D systems, Minneapolis, MN, USA) according to the manufacturer's instructions. The ELISA sensitivity of IL-6 is $0.15 \mathrm{pg} \mathrm{ml}^{-1}$.

\section{Demethylation treatment of gastric cancer cells}

To determine if SOCS-1 expression can be restored by demethylating agent, gastric cancer cell lines were subjected to $5^{\prime}$ azaDC treatment. Cells were plated and incubated for 4 days with $5 \mu \mathrm{M}$ of 5'azaDC (Sigma Chemical Co, St Louis, MO, USA).

\section{IL-6 and anti-IL-6 antibody treatment of gastric cancer cells}

After $24 \mathrm{~h}$ of serum starvation, $10 \mathrm{ng} \mathrm{ml}^{-1}$ of recombinant IL-6 (R\&D systems, Minneapolis, MN, USA) was then added into AGS cell for $15 \mathrm{~min}$ and proteins were extracted for further analysis. For antibody treatment, $10 \mu \mathrm{g} \mathrm{ml}^{-1}$ of anti-IL-6 antibody (R\&D systems) was added into the medium for $24 \mathrm{~h}$. Cells were then harvested for protein extraction and determination of the phosphorylation status of STAT3.

\section{Western blotting analysis for phospho-STAT3 and total STAT3}

Cells are washed with PBS and lysed on ice in buffer containing 1\% $\mathrm{NP}-40,50 \mathrm{~mm}$ Tris at $\mathrm{pH} 8,150 \mathrm{~mm} \mathrm{NaCl}, 5 \mathrm{~mm}$ EDTA, $10 \mu \mathrm{g} \mathrm{ml}^{-1}$ of aprotinin and pepstatin, $100 \mu \mathrm{g} \mathrm{ml}^{-1}$ of PMSF, and $100 \mathrm{mM}$ $\mathrm{NaVO}_{5}$. Protein concentration was determined using the Bio-Rad protein assay. Protein $(50 \mu \mathrm{g})$ are separated on $10 \%$ SDS polyacrylamide gel electrophoresis and transferred to nitrocellulose membrane at $100 \mathrm{~V}$ for $2 \mathrm{~h}$ at $4{ }^{\circ} \mathrm{C}$ using Bio-Rad transfer unit. The transfer buffers used are $25 \mathrm{~mm}$ Tris, $192 \mathrm{~mm}$ glycine, and $20 \%$ methanol. After transfer, the blots are blocked in $10 \%$ milk (fatty acid free) with TBS-T (0.1\% Tween-20, $20 \mathrm{~mm}$ Tris, $137 \mathrm{~mm} \mathrm{NaCl}$, and $1 \mathrm{M} \mathrm{HCl}$ ). The blots are then hybridised with anti-phosphoSTAT3 or anti-STAT3 polyclonal antibody (Cell Signaling, Beverly, MA, USA) in $1: 1000$ dilution overnight at $4{ }^{\circ} \mathrm{C}$ followed by washes in TBS-T, and then incubated with horseradish peroxidaseconjugated anti-rabbit IgG (Santa Cruz Biotechnology, Santa Cruz, CA, USA) at $1: 2000$ dilution for $1 \mathrm{~h}$ at room temperature. After several washes, blots are developed using ECL Western blotting detection kit (Amersham Biosciences, Uppsala, Sweden).

\section{RESULTS}

\section{Expression of $I L-6$ in gastric cancer cell lines}

Expression of $I L-6$ in six gastric cancer cell lines was assessed by RT - PCR. Our result showed that AGS, N87, and MKN45 expressed IL-6 (Figure 1, Table 2), while MKN28 had barely detectable IL-6 expression. IL-6 expression was absent in KATOIII and SNU16.

\section{Expression of SOCS-1 in gastric cancer cell lines}

By RT-PCR analysis, SOCS-1 was expressed in MKN45, N87, MKN28, and KATOIII (Figure 1, Table 2). Since IL-6 and other cytokines are known to upregulate the level of SOCS-1 gene (Starr et al, 1997; Song and Shuai, 1998; Schuringa et al, 2000), we also examine IL-6 level in these cell lines. Expression of IL-6 were noticed in MKN45, N87, and MKN28, suggesting that the SOCS-1 expression may be related to a negative feedback mechanism of

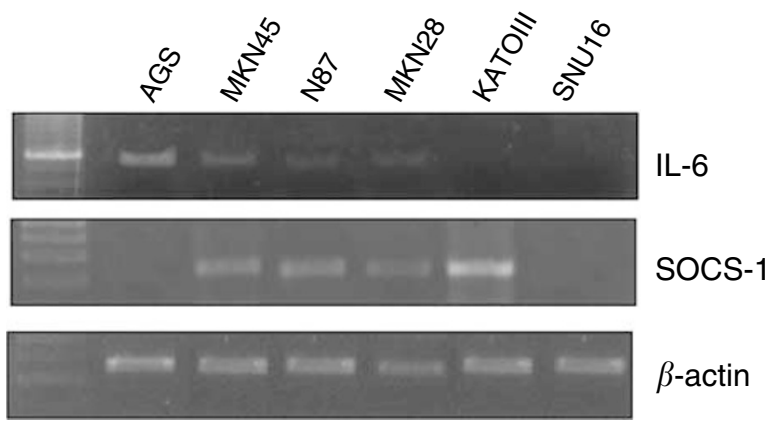

Figure I Expression of SOCS-I and IL-6 in gastric cancer cell lines by RT-PCR analysis. $\beta$-actin was performed as an internal control for loading.

Table 2 Status of SOCS-I and IL-6 in gastric cancer cell line

\begin{tabular}{lccc}
\hline & \multicolumn{3}{c}{ SOCS-I } \\
\cline { 2 - 3 } Cell line & MSP $^{\mathbf{a}}$ & RT-PCR & IL-6 $^{\mathbf{b}}$ \\
\hline AGS & $M$ & - & ++ \\
SNU-16 & $U$ & - & - \\
MKN28 & $U$ & + & + \\
MKN45 & $U$ & + & + \\
KATO III & $U$ & + & - \\
N87 & $U$ & + & + \\
\hline
\end{tabular}

SOCS-I = suppressor of cytokine signalling- I; MSP = methylation-specific PCR; RT $\mathrm{PCR}=$ reverse transcription - polymerase chain reaction; IL-6 = interleukin-6. ${ }^{\mathrm{a}}$ Result

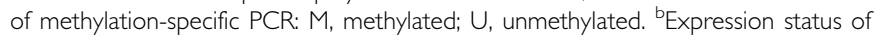

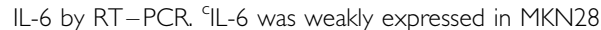

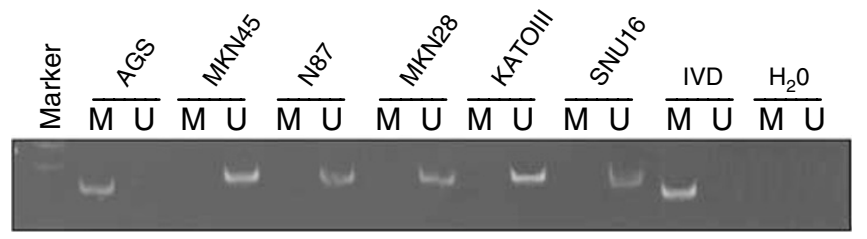

Figure 2 Methylation analysis of SOCS-I in gastric cancer cell lines by MSP PCR. $U$ indicates the presence of unmethylated genes; $M$ indicates the presence of methylated genes. In vitro methylated DNA (IVD) was used as a positive control for methylation and water $\left(\mathrm{H}_{2} \mathrm{O}\right)$ was used as a negative control for PCR.

IL-6 activation in these cell lines. In SNU16, both SOCS- 1 and IL-6 was not detected. Although KATO III does not express IL-6, other cytokines may also upregulate SOCS-1 in this cell line. Notably, despite a high level of IL- 6 expression, SOCS-1 expression was not found in AGS cells (Figure 1).

\section{IL-6 protein production in AGS cell}

To further confirm that IL- 6 protein is produced in AGS cells, we examined IL-6 level secreted by AGS cells by high-sensitivity ELISA assay. Our result showed that IL-6 production in AGS cells was $1004 \pm 130 \mathrm{ng} \mathrm{ml}^{-1}$.

\section{Methylation of SOCS-1 in gastric cancer cell lines}

By MSP among the six cancer cell lines, methylation of SOCS-1 could only be detected in AGS cell (Figure 2). Dense methylation pattern in the CpG islands of the exon 1 region of AGS cells was 


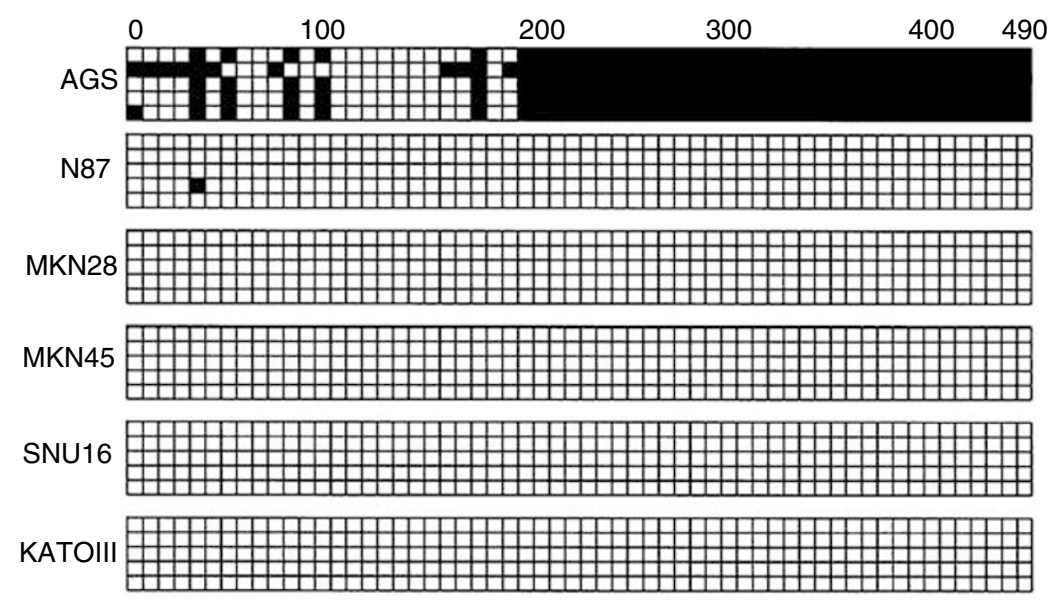

Figure 3 Bisulphite sequencing analysis of six gastric cell lines. Five randomly picked clones of PCR product from bisulphate-treated DNA were sequenced for each cell line. Black and white squares represent methylated and unmethylated CpG site, respectively. The translational start site is indicated as ' 0 '.

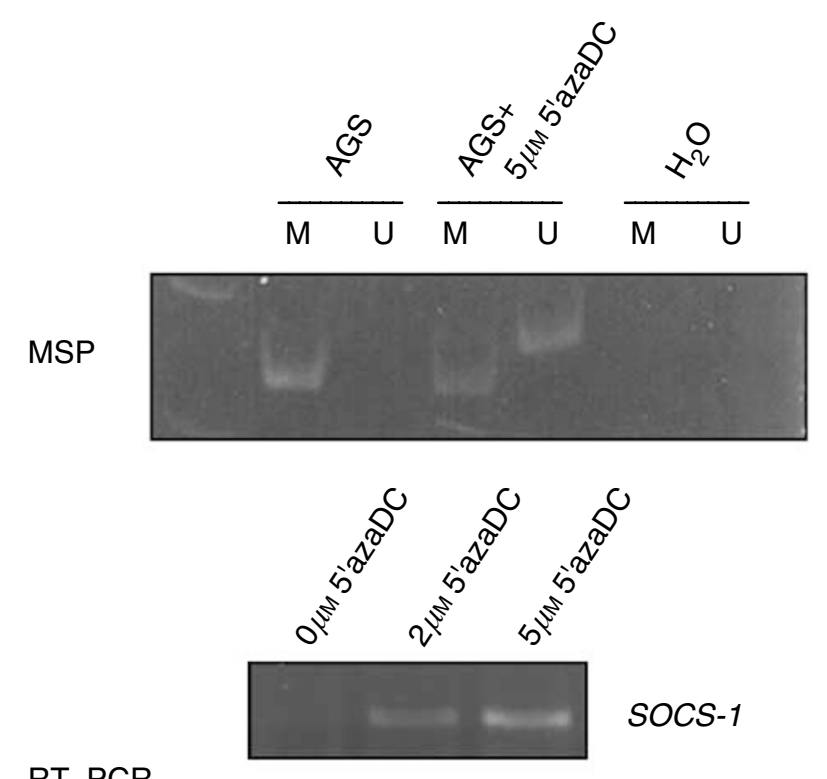

RT-PCR

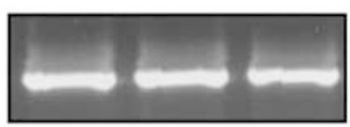

$\beta$-actin

Figure 4 Demethylation treatment of AGS cell line using 5'azaDC. AGS cell was treated with 2 or $5 \mu \mathrm{M}$ of $5^{\prime}$ azaDC for 4 days. The methylation and expression of SOCS-I was determined by MSP analysis (upper panel) and RT-PCR (lower panel).

confirmed by bisulphite DNA sequencing, while other cell lines were essentially free of methylation (Figure 3).

\section{Demethylation study of SOCS-1 in the AGS gastric cancer cell line}

Demethylation study was carried out in the AGS cell. After treatment with $5^{\prime} \mathrm{azaDC}$, expression of SOCS-1 was restored as demonstrated by RT - PCR (Figure 4, lower panel). Furthermore, MSP detected both methylated and unmethylated allele of SOCS-1, indicating that demethylation of the gene occurred (Figure 4,

\begin{tabular}{|c|c|c|c|c|c|}
\hline 5'azaDC & - & + & - & + & - \\
\hline Anti-IL-6 Ab & - & - & - & - & + \\
\hline IL-6 & - & - & + & + & - \\
\hline p-STAT3 & & & & & \\
\hline STAT3 & & & & & \\
\hline$\beta$-actin & & & & & \\
\hline
\end{tabular}

Figure 5 Effect of various treatments on phosphorylation of STAT3 protein in AGS cells. After treatment, cells were harvested for protein extraction and subjected to Western blot analysis with anti-phosphoSTAT3 antibody to examine the phosphorylation status of STAT3 protein As a control, the blot was also probed with total STAT3 and $\beta$-actin Starting from left, AGS cells were untreated (panel I) or treated with 5'azaDC for 4 days (panel 2); recombinant IL-6 for 15 min (panel 3); 5 'azaDC for 4 days and then recombinant IL-6 for 15 min (panel 4); or antiIL-6 antibody for $24 \mathrm{~h}$ (panel 5).

upper panel). These results confirmed that loss of expression of SOCS-1 in the AGS cell was related to gene methylation.

\section{STAT3 activation in AGS gastric cancer cell line}

Constitutive activation of STAT3 was found in the AGS cells in which IL-6 was highly expressed (Figure 5, lane 1). We further restored SOCS-1 expression in AGS cell by treating the cell with 5 azaDC. In addition to the re-expression of SOCS-1, it was accompanied by reduction in phosphorylation of STAT3 (Figure 5, lane 2). Pretreatment with anti-IL-6 antibody for $24 \mathrm{~h}$ also resulted in inhibition of phosphorylation of STAT3 but not as marked as 5'azaDC treatment (Figure 5, lane 5). Addition of recombinant IL-6 in the medium for $15 \mathrm{~min}$ resulted in the reactivation of STAT3 phosphorylation in 5'azaDC-treated AGS cells (Figure 5, lane 4), suggesting that IL-6 was responsible for STAT3 activation. Taken together, these findings suggested that SOCS-1 play an important role in the inhibition of IL-6-mediated STAT3 activation in AGS gastric cancer cell line. 
Methylation status and expression of SOCS-1 in primary gastric cancer

Methylation of SOCS-1 was found in $27.5 \%$ (11 of 40 ) of gastric cancer samples and $10 \%$ (one of 10 ) of adjacent normal mucosa (Figure 6). Among these 40 gastric cancer samples, no correlation between methylation status of SOCS-1 with $H$. pylori status, histological type or staging was observed (Table 3 ). On the other hand, SOCS-1 methylation was not found in the normal gastric mucosa from nine individuals without gastric cancer (Figure 6). To further investigate the expression status of SOCS-1 in these gastric cancer tissues, total RNA from 14 gastric cancer samples and the corresponding normal tissues were extracted for RT-PCR analysis. Downregulation of SOCS-1 was observed in two (14\%) gastric tumour tissues, which also showed SOCS-1 methylation

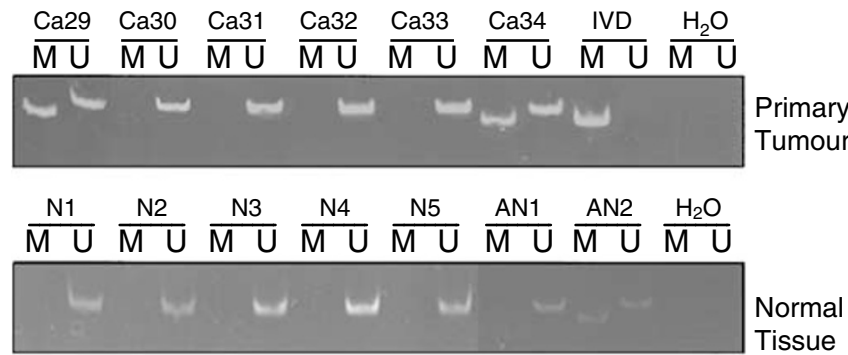

Figure 6 Methylation analysis of SOCS-I in primary gastric cancer samples and normal samples by MSP. The upper panel displayed result of cancer samples ( $\mathrm{Ca}$ ) and lower panel displayed the result of normal samples ( $\mathrm{N}$ ) and adjacent noncancer samples (AN).

Table 3 Association between SOCS-I methylation and clinicopathological parameters of gastric cancer

\begin{tabular}{|c|c|c|c|}
\hline & Total no. & SOCS-I methylation (\%) ${ }^{\mathrm{a}}$ & $P$-value ${ }^{\text {b }}$ \\
\hline Sex & & & 0.347 \\
\hline Male & 24 & $6(25.0)$ & \\
\hline Female & 16 & $5(31.3)$ & \\
\hline Age (years) & & & 0.404 \\
\hline$\geqslant 60$ & 26 & $8(30.7)$ & \\
\hline$<60$ & 14 & $3(21.4)$ & \\
\hline H. pylori status & & & 0.305 \\
\hline Positive & 19 & $4(21.1)$ & \\
\hline Negative & 21 & $7(33.3)$ & \\
\hline Site & & & 0.510 \\
\hline Antrum & 21 & $6(28.5)$ & \\
\hline Body & 11 & $4(36.3)$ & \\
\hline Cardiac & 8 & I (12.5) & \\
\hline Staging ${ }^{c}$ & & & 0.596 \\
\hline 1 & 7 & $2(28.5)$ & \\
\hline$\|$ & 6 & $3(50)$ & \\
\hline III & 19 & $4(21.1)$ & \\
\hline IV & 7 & $2(28.5)$ & \\
\hline Lauren classification & & & 0.875 \\
\hline Intestinal type & 19 & $4(21.1)$ & \\
\hline Diffuse Type & 17 & $5(29.4)$ & \\
\hline Mixed type & 4 & $2(50.0)$ & \\
\hline
\end{tabular}

SOCS-I = suppressor of cytokine signalling- $I$. ${ }^{\text {aNumber }}$ of methylated cases, numbers within parentheses are percentages. ${ }^{b}$ Comparison were made by $\chi^{2}$-test or Fisher's exact test (SPSS 10.0). 'Staging according to American Joint Committee on Cancer. Data (staging were not available in one case).
(Figure 7, Table 4). These result suggested that methylation of SOCS-1 gene was responsible for the downregulation of the gene in primary gastric cancer.

\section{DISCUSSION}

Activation of interleukin-mediated JAK/STAT pathway has been recently described to play a crucial role in human cancer development. Constitutive activation of STAT3 has been observed in breast cancer, prostate cancer and leukaemia (Schuringa et al, 2000; Lin et al, 2000b; Campbell et al, 2001; Li and Shaw, 2002). Recent studies also found that blockade of STAT3 activity by the expression of the dominant-negative STAT3 can inhibit growth of AGS gastric cancer cell line, thus further suggesting that JAK/STAT may play an important role in development of gastric cancer (Kanai et al, 2003). On the other hand, inactivation of the negative regulator, SOCS-1, also leads to the activation of the JAK/STAT pathway. Downregulation of SOCS-1 by gene promoter hypermethylation has been recently reported in $65 \%$ of HCC cell line, $62.9 \%$ of multiple myeloma patients samples and $31.6 \%$ of pancreatic cancer cell lines with resultant activation of STAT3 (Yoshikawa et al, 2001; Fukushima et al, 2003; Galm et al, 2003). Moreover, restoration of SOCS-1 suppresses tumour growth in

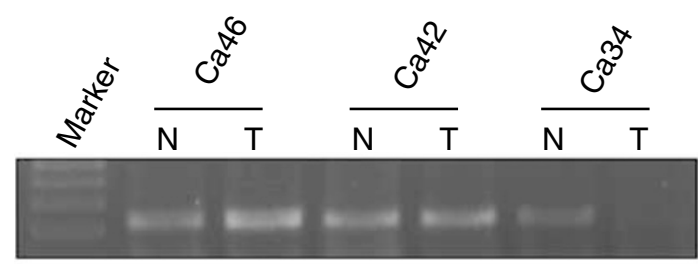

SOCS-1

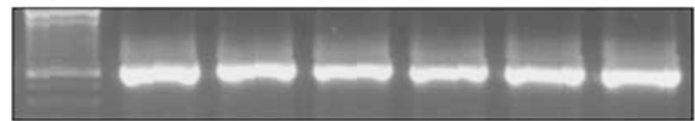

$\beta$-actin

Figure 7 Expression of SOCS-I in primary tumour and corresponding normal tissue by RTPCR. Decreased expression of SOCS-I was found in tumour samples of case 34 where methylation of SOCS-I was also found (Figure 6). $\mathrm{T}$ indicates gastric cancer sample and $\mathrm{N}$ indicates corresponding normal sample. Expression of $\beta$-actin was also performed (lower panel) to ensure equal loading.

Table 4 Methylation and expression status of SOCS-I in 14 primary gastric cancer samples

\begin{tabular}{lllcl}
\hline & & & \multicolumn{2}{c}{ soCS-I } \\
\cline { 4 - 5 } Case & Type & Site & Methylation & Expression \\
\hline Ca21 & Intestinal & Antrum & $\cup$ & NC \\
Ca22 & Intestinal & Cardiac & $\cup$ & NC \\
Ca24 & Diffuse & Cardiac & $\cup$ & NC \\
Ca27 & Diffuse & Body & $M$ & Down \\
Ca28 & Intestinal & Body & $\cup$ & NC \\
Ca32 & Intestinal & Body & $\cup$ & NC \\
Ca33 & Intestinal & Body & $\cup$ & NC \\
Ca34 & Mixed & Antrum & M & Down \\
Ca36 & Mixed & Antrum & $M$ & NC \\
Ca38 & Mixed & Cardiac & $\cup$ & NC \\
Ca41 & Diffuse & Cardiac & $\cup$ & NC \\
Ca42 & Intestinal & Antrum & $\cup$ & NC \\
Ca46 & Intestinal & Antrum & $\cup$ & NC \\
Ca47 & Diffuse & Antrum & $\cup$ & NC \\
\hline
\end{tabular}

SOCS-I = suppressor of cytokine signalling-I; $M=$ methylated; $U=$ unmethylated; NC, no change; Down, downregulation. 
HCC and haematopoietic malignancy (Frantsve et al, 2001; Yoshikawa et al, 2001; Rottapel et al, 2002).

In this study, we have found that $I L-6$ was endogenously expressed in several gastric cancer cell lines. Since expression of IL-6 upregulates SOCS-1, which participates in the negative regulation of the JAK/STAT pathway (Starr et al, 1997; Song and Shuai, 1998; Losman et al, 1999; Schuringa et al, 2000), we further analysed the expression of SOCS-1 in these gastric cancer cell lines. Both $I L-6$ and SOCS-1 was not expressed in SUN-16 and the results suggested that this pathway might not be involved in this cell line. Concomitant expression of $I L-6$ and SOCS- 1 can be observed in most gastric cancer cell lines, except KATOIII and AGS cell. To further confirm that IL-6 protein is produced in AGS cells, we examined IL- 6 level by ELISA assay. IL-6 level of $1004 \mathrm{ng} \mathrm{ml}^{-1}$ is found in condition medium of AGS cells, which is consistent with previous report (Crawford et al, 2003). Nevertheless, it was interesting to note that SOCS-1 was not expressed in AGS cells despite the expression of IL-6. We then analysed the methylation status of this gene in AGS cells. Methylation studies by both MSP analysis and bisulphite sequencing confirmed that $\mathrm{CpG}$ island of SOCS-1 was methylated in AGS cells but not other cell lines. Although KATO III did not express IL-6, the high level of SOCS-1 detected may act as a negative regulation for other cytokines expressed in this cell line (Haque et al, 2000; Cottet et al, 2001; Naka et al, 2001; Eyles et al, 2002).

In order to investigate the functional consequences of SOCS-1 inactivation in JAK/STAT pathway, we analysed the phosphorylation status of STAT3 protein in AGS cells. Under the condition that SOCS-1 was inactivated by methylation, STAT3 was in hyperphosphorylated state. Restoring SOCS-1 expression by treating the cells with demethylation agent, phosphorylation of STAT3 was effectively suppressed. On the other hand, blocking the endogenous IL-6 by anti-IL-6 antibody can partially suppress STAT3 activity. Furthermore, addition of recombinant IL-6 restored STAT3 phosphorylation in demethylated-AGS cell, thus suggesting that IL-6 was responsible for STAT3 activation. Taken together, these results suggested that SOCS-1 was important for the downregulation of JAK/STAT signalling. Methylation-mediated SOCS-1 inactivation enhanced IL-6-mediated activation of STAT3 in AGS cell.

\section{REFERENCES}

Burke WM, Jin X, Lin HJ, Huang M, Liu R, Reynolds RK, Lin J (2001) Inhibition of constitutively active STAT3 suppresses growth of human ovarian and breast cancer cells. Oncogene 20: 7925-7934

Campbell CL, Jiang Z, Savarese DM, Savarese TM (2001) Increased expression of the interleukin-11 receptor and evidence of STAT3 activation in prostate carcinoma. Am J Pathol 158: 25-32

Chan AS, To KF, Lo KW, Mak KF, Pak W, Chiu B, Tse GM, Ding M, Li X, Lee JC, Huang DP (2000) High frequency of chromosome 3p deletion in histologically normal nasopharyngeal epithelia from southern Chinese. Cancer Res 60: $5365-5370$

Cottet S, Dupraz P, Hamburger F, Dolci W, Jaquet M, Thorens B (2001) SOCS-1 protein prevents Janus kinase/STAT-dependent inhibition of beta cell insulin gene transcription and secretion in response to interferon-gamma. J Biol Chem 276: 25862-25870

Crawford HC, Krishna US, Israel DA, Matrisian LM, Washington MK, Peek Jr RM (2003) Helicobacter pylori strain-selective induction of matrix metalloproteinase-7 in vitro and within gastric mucosa. Gastroenterology 125: $1125-1136$

De Vos J, Jourdan M, Tarte K, Jasmin C, Klein B (2000) JAK2 tyrosine kinase inhibitor tyrphostin AG490 downregulates the mitogen-activated protein kinase (MAPK) and signal transducer and activator of transcription (STAT) pathways and induces apoptosis in myeloma cells. Br J Haematol 109: 823-828

Endo TA, Masuhara M, Yokouchi M, Suzuki R, Sakamoto H, Mitsui K, Matsumoto A, Tanimura S, Ohtsubo M, Misawa H, Miyazaki T, Leonor N, Taniguchi T, Fujita T, Kanakura Y, Komiya S, Yoshimura A (1997) A
Moreover, methylation of SOCS-1 can be detected in about $30 \%$ of primary tumour tissues and $10 \%$ of adjacent normal tissues. Downregulation of SOCS-1 was also observed in primary gastric cancer with methylation of SOCS-1. Although downregulation of SOCS-1 was not observed in one sample (Ca36) in which methylation of SOCS-1 was detected, this discrepancy may be due to heterogeneity of the tumours in which only a small portion of tumour cells have SOCS-1 methylation. Nevertheless, in this study, we have demonstrated that SOCS-1 was silenced by hypermethylation in the AGS cell line and a subset of primary gastric tumour tissues. It is also worth noting to point out that hypermethylation of SOCS-1 was also found in $10 \%$ of adjacent normal tissue and this observation suggest that SOCS-1 methylation may also be involved in the early gastric carcinogenesis process.

Recently, we and others have found that eradication of H. pylori in the stomach can reduce the risk of gastric cancer (Uemura et al, 1997; Saito et al, 2000; Sung et al, 2000). The current study may provide clue to the underlying mechanism that $H$. pylori-mediated cytokine expression-enhanced tumour progression in a subset of gastric cancer where SOCS-1 was hypermethylated. Inhibition of JAK/STAT pathway by demethylation treatment or by applying specific JAK2 inhibitor may open up a new therapeutic strategy against gastric cancer (De Vos et al, 2000; Burke et al, 2001; Yoshikawa et al, 2001)

In summary, loss of expression of SOCS-1 in AGS cell line was related to gene promoter hypermethylation. This phenomenon together with endogenous $I L-6$ expression leads to the activation of STAT3 protein. The increase of STAT3 activity together with overexpression of cytokine in this gastric cancer cell line suggested that alteration of JAK/STAT was important in a subset of gastric cancer.

\section{ACKNOWLEDGEMENTS}

This study was supported by the Direct Grant (project number 2003.1.043) for Research of the Chinese University of Hong Kong. new protein containing an $\mathrm{SH} 2$ domain that inhibits JAK kinases. Nature 387: $921-924$

Eyles JL, Metcalf D, Grusby MJ, Hilton DJ, Starr R (2002) Negative regulation of interleukin-12 signaling by suppressor of cytokine signaling-1. J Biol Chem 277: 43735-43740

Frantsve J, Schwaller J, Sternberg DW, Kutok J, Gilliland DG (2001) Socs-1 inhibits TEL-JAK2-mediated transformation of hematopoietic cells through inhibition of JAK2 kinase activity and induction of proteasome-mediated degradation. Mol Cell Biol 21: 3547-3557

Fukushima N, Sato N, Sahin F, Su GH, Hruban RH, Goggins M (2003) Aberrant methylation of suppressor of cytokine signalling-1 (SOCS-1) gene in pancreatic ductal neoplasms. $\mathrm{Br} J$ Cancer 89: $338-343$

Galm O, Yoshikawa H, Esteller M, Osieka R, Herman JG (2003) SOCS-1, a negative regulator of cytokine signaling, is frequently silenced by methylation in multiple myeloma. Blood 101: 2784-2788

Giri D, Ozen M, Ittmann M (2001) Interleukin-6 is an autocrine growth factor in human prostate cancer. Am J Pathol 159: 2159-2165

Graham DY (1997) Helicobacter pylori infection in the pathogenesis of duodenal ulcer and gastric cancer: a model. Gastroenterology 113: $1983-1991$

Haque SJ, Harbor PC, Williams BR (2000) Identification of critical residues required for suppressor of cytokine signaling-specific regulation of interleukin-4 signaling. J Biol Chem 275: 26500-26506

Hwang IR, Hsu PI, Peterson LE, Gutierrez O, Kim JG, Graham DY, Yamaoka Y (2003) Interleukin-6 genetic polymorphisms are not related 
to Helicobacter pylori-associated gastroduodenal diseases. Helicobacter 8: $142-148$

Kabir S, Daar GA (1995) Serum levels of interleukin-1, interleukin-6 and tumour necrosis factor-alpha in patients with gastric carcinoma. Cancer Lett 95: $207-212$

Kanai M, Konda Y, Nakajima T, Izumi Y, Kanda N, Nanakin A, Kubohara Y, Chiba $\mathrm{T}$ (2003) Differentiation-inducing factor-1 (DIF-1) inhibits STAT3 activity involved in gastric cancer cell proliferation via MEKERK-dependent pathway. Oncogene 22: 548-554

Kuipers EJ, Meuwissen SG (1996) Helicobacter pylori and gastric carcinogenesis. Scand J Gastroenterol Suppl 218: 103-105

Li L, Shaw PE (2002) Autocrine-mediated activation of STAT3 correlates with cell proliferation in breast carcinoma lines. J Biol Chem 277: $17397-17405$

Lin CT, Kao HJ, Lin JL, Chan WY, Wu HC, Liang ST (2000a) Response of nasopharyngeal carcinoma cells to Epstein-Barr virus infection in vitro. Lab Invest 80: $1149-1160$

Lin TS, Mahajan S, Frank DA (2000b) STAT signaling in the pathogenesis and treatment of leukemias. Oncogene 19: 2496-2504

Losman JA, Chen XP, Hilton D, Rothman P (1999) Cutting edge: SOCS-1 is a potent inhibitor of IL-4 signal transduction. J Immunol 162: $3770-3774$

Nagai H, Kim Y, Konishi N, Baba M, Kubota T, Yoshimura A, Emi M (2002) Combined hypermethylation and chromosome loss associated with inactivation of SSI-1/SOCS-1/JAB gene in human hepatocellular carcinomas. Cancer Lett 186: 59-65

Naka T, Tsutsui H, Fujimoto M, Kawazoe Y, Kohzaki H, Morita Y, Nakagawa R, Narazaki M, Adachi K, Yoshimoto T, Nakanishi K, Kishimoto T (2001) SOCS-1/SSI-1-deficient NKT cells participate in severe hepatitis through dysregulated cross-talk inhibition of IFN-gamma and IL-4 signaling in vivo. Immunity 14: 535-545

Nicholson SE, Willson TA, Farley A, Starr R, Zhang JG, Baca M, Alexander WS, Metcalf D, Hilton DJ, Nicola NA (1999) Mutational analyses of the SOCS proteins suggest a dual domain requirement but distinct mechanisms for inhibition of LIF and IL-6 signal transduction. EMBO J 18: $375-385$

Okochi O, Hibi K, Sakai M, Inoue S, Takeda S, Kaneko T, Nakao A (2003) Methylation-mediated silencing of SOCS-1 gene in hepatocellular carcinoma derived from cirrhosis. Clin Cancer Res 9: 5295-5298

O'Shea JJ, Gadina M, Schreiber RD (2002) Cytokine signaling in 2002: new surprises in the Jak/Stat pathway. Cell 109(Suppl): S121-S131

Pisani P, Parkin DM, Ferlay J (1993) Estimates of the worldwide mortality from eighteen major cancers in 1985. Implications for prevention and projections of future burden. Int J Cancer 55: 891-903
Rottapel R, Ilangumaran S, Neale C, La Rose J, Ho JM, Nguyen MH, Barber D, Dubreuil P, de Sepulveda P (2002) The tumour suppressor activity of SOCS-1. Oncogene 21: $4351-4362$

Saito K, Arai K, Mori M, Kobayashi R, Ohki I (2000) Effect of Helicobacter pylori eradication on malignant transformation of gastric adenoma. Gastrointest Endosc 52: 27-32

Schneider MR, Hoeflich A, Fischer JR, Wolf E, Sordat B, Lahm H (2000) Interleukin-6 stimulates clonogenic growth of primary and metastatic human colon carcinoma cells. Cancer Lett 151: $31-38$

Schuringa JJ, Wierenga AT, Kruijer W, Vellenga E (2000) Constitutive Stat3, Tyr705, and Ser727 phosphorylation in acute myeloid leukemia cells caused by the autocrine secretion of interleukin-6. Blood 95: $3765-3770$

Song MM, Shuai K (1998) The suppressor of cytokine signaling (SOCS) 1 and SOCS3 but not SOCS2 proteins inhibit interferon-mediated antiviral and antiproliferative activities. J Biol Chem 273: 35056-35062

Starr R, Willson TA, Viney EM, Murray LJ, Rayner JR, Jenkins BJ, Gonda TJ, Alexander WS, Metcalf D, Nicola NA, Hilton DJ (1997) A family of cytokine-inducible inhibitors of signalling. Nature 387: $917-921$

Sung JJ, Lin SR, Ching JY, Zhou LY, To KF, Wang RT, Leung WK, Ng EK, Lau JY, Lee YT, Yeung CK, Chao W, Chung SC (2000) Atrophy and intestinal metaplasia one year after cure of $H$. pylori infection: a prospective, randomized study. Gastroenterology 119: 7-14

Uemura N, Mukai T, Okamoto S, Yamaguchi S, Mashiba H, Taniyama K, Sasaki N, Haruma K, Sumii K, Kajiyama G (1997) Effect of Helicobacter pylori eradication on subsequent development of cancer after endoscopic resection of early gastric cancer. Cancer Epidemiol Biomarkers Prev 6: $639-642$

Wu CW, Wang SR, Chao MF, Wu TC, Lui WY, P'Eng FK, Chi CW (1996) Serum interleukin-6 levels reflect disease status of gastric cancer. Am J Gastroenterol 91: 1417-1422

Yamaoka Y, Kita M, Kodama T, Sawai N, Imanishi J (1996) Helicobacter pylori cagA gene and expression of cytokine messenger RNA in gastric mucosa. Gastroenterology 110: $1744-1752$

Yamaoka Y, Kodama T, Kita M, Imanishi J, Kashima K, Graham DY (2001) Relation between cytokines and Helicobacter pylori in gastric cancer. Helicobacter 6: 116-124

Yoshikawa H, Matsubara K, Qian GS, Jackson P, Groopman JD, Manning JE, Harris CC, Herman JG (2001) SOCS-1, a negative regulator of the JAK/STAT pathway, is silenced by methylation in human hepatocellular carcinoma and shows growth-suppression activity. Nat Genet 28: $29-35$ 